\title{
EFFECTS OF ARTICHOKE (Cynara scolumus L.) EXTRACT ON BIOCHEMICAL PARAMETERS IN DIABETIC RATS
}

\author{
Isabela Alves ${ }^{1}$, Brenna Carvalho ${ }^{1}$, Michele Terra ${ }^{1}$, Carlos Henrique Oliveira ${ }^{2}$, Aldo Silva ${ }^{1}$, \\ Marcelo Costa ${ }^{1}$, Regiane Rodrigues ${ }^{1}$, Gersika Barros ${ }^{1}$, and Bruno Salles ${ }^{1}$ \\ ${ }^{1}$ UNIFENAS \\ ${ }^{2}$ Universidade José do Rosário Vellano
}

October 8, 2020

\begin{abstract}
Diabetes mellitus is among the chronic diseases considered emergencies. Products obtained from medicinal plants have been used for thousands of years by the population in the treatment of various diseases. The objective of this work was to evaluate the possible effects of inputs obtained from the artichoke (Cynara scolumus L.) on biochemical markers in diabetic rats. The dry extract was obtained by hydroethanolic $(70 \% \mathrm{v} / \mathrm{v})$ maceration. Male Wistar rats were treated with alloxan (150 mg / $\mathrm{kg}$ of mass dissolved in $0.9 \%$ saline) intraperitoneally. The extract $(0.2 \mathrm{~g}$ extract $/ \mathrm{kg})$ was given in normal and diabetic rats for 30 days. Animals from the Control and Diabetes groups received only water. Biochemical markers were determined in the serum by enzymatic colorimetric method. The chemical characterization was performed quantifying the total polyphenol content (Folin-Ciocalteau) and quantification of the total flavonoid in dry extract $(1 \mathrm{mg} / \mathrm{mL})$, by the complexation method with aluminum chloride. The evaluation of fasting blood glucose was positive, when considered that the glycemic levels from "diabetic group" was partially higher when compared with "water group", "extract group" and "diabetic extract group". The treatment with extract for the diabetic animals also prevented significantly the serum levels of fructosamine and presented serum levels of total cholesterol and triglycerides significantly lower than non-treated animals. However, the treatment with artichoke extract was able to control glycemic levels at short and medium term, showing an improvement in lipid profile. Key words: Artichoke. Oxidative stress. Phytochemical screening. Flavonoids. Total polyphenols.
\end{abstract}

\begin{abstract}
Diabetes mellitus is among the chronic diseases considered emergencies. Products obtained from medicinal plants have been used for thousands of years by the population in the treatment of various diseases. The objective of this work was to evaluate the possible effects of inputs obtained from the artichoke (Cynara scolumus L.) on biochemical markers in diabetic rats. The dry extract was obtained by hydroethanolic $(70 \%$ $\mathrm{v} / \mathrm{v}$ ) maceration. Male Wistar rats were treated with alloxan (150 mg / $\mathrm{kg}$ of mass dissolved in $0.9 \%$ saline) intraperitoneally. The extract $(0.2 \mathrm{~g}$ extract $/ \mathrm{kg})$ was given in normal and diabetic rats for 30 days. Animals from the Control and Diabetes groups received only water. Biochemical markers were determined in the serum by enzymatic colorimetric method. The chemical characterization was performed by quantifying the total polyphenol content by the Folin-Ciocalteau method and quantification of the total flavonoid in dry extract $(1 \mathrm{mg} / \mathrm{mL}$ ), by the complexation method with aluminum chloride. The evaluation of fasting blood glucose was positive, when considered that the glycemic levels from "diabetic group" was partially higher when compared with "water group", "extract group" and "diabetic extract group". The treatment with extract for the diabetic animals also prevented significantly the serum levels of fructosamine and presented serum levels of total cholesterol and triglycerides significantly lower than non-treated animals. However, the treatment with artichoke extract was able to control glycemic levels at short and medium term, showing an improvement in lipid profile.
\end{abstract}


Key words: Artichoke. Oxidative stress. Phytochemical screening. Flavonoids. Total polyphenols.

\section{INTRODUCTION}

Chronic noncommunicable diseases (NCDs) cause about 16 millions of premature deaths per annum. According to the annual report of the World Health Organization's (WHO), published in 2016, heart diseases and lung diseases, cerebrovascular accidents, cancer and diabetes are largely responsible for high rates of premature deaths. In Brazil, studies point to three major groups responsible for the "NCDs epidemic", diabetes, cardiovascular disease and brain stroke [Malta \& Silva, 2013].

The diabetes mellitus is featured by a chronic disorder that affects the metabolism of carbohydrates, fats and proteins. The diabetes mellitus (DM) is considered a public health problem due to its association to several risk complications, such as microvascular changes, in which retinopathy, neuropathy and macrovascular complications can be cited, including coronary heart disease and stroke.

Of chronic complications inherent to diabetes mellitus, diabetic neuropathy and cardiopathy according to [Moreira et al., 2008], affects about $30 \%$ to $40 \%$ of individuals with type $1 \mathrm{DM}$ and about $10 \%$ to $40 \%$ those with type $2 \mathrm{DM}$, representing the main macrovascular complication of diabetes and the biggest cause of end-stage renal failure worldwide.

Therefore, the search for compounds with capacity to reduce or prevent chronic complications of diabetes mellitus, have been the target of several studies since the costs for the treatment of NCDS have a great impact on the country's health system. Otherwise, use of natural products has been a good source for discovery of new drugs. Only for the treatment of type 1 and 2 diabetes mellitus, from 1981 to 2014, 29 new drugs from natural sources have been approved [Newman \& Cragg, 2016 ].

\section{METHODOLOGY}

As a natural source, leaves from Artichoke (Cynara scolumus L .) were used to extract production and purchased from a company which produces plant extracts, Biotae(C).

\subsection{Crude extraction preparation}

Dried and sprayed artichoke leaves (Cynara scolumus L.) were submitted to exhaustive maceration, in proportion of 1 part of powder to 10 parts of hydroethanolic solution at $70 \%(\mathrm{v} / \mathrm{v})$. The mixture (powder + extractor liquid) was filtered through a paper filter and the extractive solution (extractor liquid + secondary liquid) was dried under reduced pressure at $45^{\circ} \mathrm{C}$, eliminating the organic solvent. The water was removed by the lyophilization process. After the organic and aqueous solvent elimination, crude extract was stored at $-20^{\circ} \mathrm{C}$.

\subsection{Determination of the total phenol content}

The content of polyphenols was determined in crude extract aliquots by the method of Folin \& Ciocalteau, using gallic acid as standard [Singleton, Orthofer \& Lamulela, 1999]. The results were expressed in grams equivalent of gallic acid (g GAE/100g extract). All determinations were performed in triplicate.

\subsection{Determination of flavonoids content}

The content of total flavonoid content in crude extract was performed in solutions containing the crude extract $(1 \mathrm{mg} / \mathrm{mL})$, Fr-BuOH $(0,2 \mathrm{mg} / \mathrm{mL})$ and Fr-EtOAc $(0,2 \mathrm{mg} / \mathrm{mL})$. Stable complexation between aluminum and flavonoids in a solution containing methanol or ethanol was quantified by spectrophotometry at 425 $\mathrm{nm}$, since at this wavelength it is possible to quantify the flavonoid content without the interference of phenolic compounds. [Souza, 2005] Quercetin in ethanolic solution was used as standard at concentrations of $10,20,40,60,80,100 \mu \mathrm{g} / \mathrm{mL}$, obtaining the analytical curve. The flavonoid content was determined by interpolating the absorbance of the samples against the calibration curve and the values were expressed as quercetin equivalent ( $\mathrm{g}$ of quercetin/100g of sample). The analyzes were performed in triplicate.

2.4 Experimental Groups 
The animals used in this experiment were Wistar lineage rats, male and aging 8 weeks and body mass of $(326,64 \mathrm{~g}, \pm 28,5)$. [King, 2012]. Animals were obtained from the Central vivarium of José do Rosário Vellano university. The entire experimental part of this work was approved by the ethics committee on animal experimentation under approval number $09 \mathrm{~A} / 2018$. The animals were housed at vivarium the laboratory of pharmacology and experimental biochemistry, with a maximum of 5 animals per polyethylene box, type kaefiq, autoclavable, acid resistant, in the measures of 49X34X16 cm. Initially, the animals were submitted to a vermifugation protocol with albendazol $10 \%$ in cycles of 24 to 48 hours ad libitum during 1 week. Water and feed were replenished daily ad libitum to the animals.

Animals groups were divided into four groups:

a) Non-diabetic group: was composed of non-diabetics animals and were not subjected to treatment with the artichoke extract $(\mathrm{n}=5)$.

b) Diabetic group: was composed of animals subjected to treatment with the alloxan and not treated with artichoke extract $(\mathrm{n}=6)$.

c) Extract group: was composed for non-diabetic animals and treated with artichoke extract $(\mathrm{n}=10)$.

d) Diabetic extract group: was composed for animals subjected to treatment with alloxan and treated with artichoke extract $(\mathrm{n}=14)$.

\subsection{Induction of diabetes mellitus}

To induce diabetes, the diabetogenic drug, alloxan, was administered in rats, intraperitoneally, at a concentration of $150 \mathrm{~m} \mathrm{mg} / \mathrm{Kg}$ of body weight, dissolved in saline solution $0,9 \%$ ( $\mathrm{pH} 4,5)$. The animals which showed casual blood glucose over $200 \mathrm{mg} / \mathrm{dL}$ were considered diabetics and evenly distributed between diabetic groups so that all groups had a statistically equal glycemic [Jaouhari, Lazrek \& Jana, 2000].

\subsection{Crude extract administration}

Crude extract was reconstituted in water and administered for gavage technique for 30 days. The amount of crude extract administered to the animals was $200 \mathrm{mg}$ of extract per kilogram of animal mass [Gary, 2003].

\subsection{Biological parameters}

The Biological parameters were evaluated during the treatment of the animals, by monitoring food consumption and liquid intake. At the end of the treatment, the animals were anesthetized to get the blood collected and conducted biochemical tests for these samples.

\subsection{Obtaining biological samples}

At day 31 , the animals were anesthetized with thiopental $(60 \mathrm{mg} / \mathrm{kg}$ of mass) intraperitoneally and the blood was collected by cardiac puncture and distributed in different tubes without additives and with a clot activator gel to obtain the serum.

\subsection{Evaluation of glycemic control}

To evaluate the glycemic control, fasting blood glucose and fructosamine parameters were measured. The glucose concentration was measured in the serum by an endpoint colorimetric enzymatic method. The determination of serum fructosamine concentration was made by a colorimetric kinetic method, based on the reduction of nitrobluetetrazole, in semi-automated equipment from the Bio2000@ brand com kits da marca labtest $\AA$.

2.10 Evaluation of the lipid profile

The concentration of total cholesterol and triglycerides were determined in the serum by an endpoint colorimetric enzymatic method da marca labtest $\mathbb{R}$ [Burtis \& Ashwood, 1999].

2.11 Determinação de creatinina 
Os níveis séricos de creatinina serão determinados pelo método de Jaffé modificado, utilizando kit adquirido comercialmente, cujo procedimento de medição foi calibrado com o material de referência SRM 914 doNational Institute of Standards and Technology (NIST), tornando os resultados rastreáveis ao método definitivo (espectrometria de massas com diluição isotópica) [Burtis \& Ashwood, 1999].

\subsection{Statistical analysis}

The observed values of each variable were subjected to analysis of variance. Multiple comparisons between the means of the different treatments were performed using Tukey test at $5 \%$ of probability in the Sisvar version 5.3 program.

\section{RESULTS AND DISCUSSIONS}

Phenolic compounds in natural products compose a chemically heterogeneous group, with approximately 10.000 compounds. The solubility of phenolic compounds is induced by the polarity of the solvent used, some of which are soluble only in organic solvents, while others, such as carboxylic acid and glycosides are solubles in polar solvents [Miranda et al., 2016]. The content of total polyphenols can vary according to the different parts of the plant species used, as well as the type of solvent used in its extraction. The main chemical components of the artichoke are polyphenols, mainly flavonoids, and their quantification is extremely important to measure the quality of raw material in study.

In experiments developed at our laboratory, the presence of total polyphenols content in the artichoke extract was related, using 2,0 $\pm 0,2 \mathrm{~g}$ EAG/100 g of dry extract. The content of total polyphenols found in the artichoke crude extract was similar to the values reported in the literature [Ramaiya, Bujang \& Zakaria, 2014]. However, the values found in the artichoke leaves in our study were higher than those which were obtained by [Kelly et al, 2013] $(0.83 \pm 0.07 \mathrm{~g} \mathrm{EAG/100g})$ and less than values found by [Ramaiya, Bujang \& Zakaria, 2014] (9.25 g EAG/100g) even in other plant species, such as P. Edulis. This divergence can be attributed to the variations between the different plants, as well as the solvents employed in these studies [Ramaiya, Bujang \& Zakaria, 2014].

On other hand, the determination of total flavonoid demonstrated the presence of $3,04 \mathrm{mgEQ} / 100 \mathrm{~g}$ of extract. According to the same authors, the efficiency of the extraction depends not only on the polarity of the solvent used, but on the affinity of the solute for the extraction solvent, the ratio of the phases and number of extractions.

Due to the instability of the secondary metabolites present in the artichoke extracts and responsible for their therapeutic activities, several analytical methods have been developed for the determination and separation of these compounds. Therefore, the quantification of the markers is essential to ensure therapeutic efficiency. On other hand, the analysis of flavonoids levels is extremely important because it is the precedent for falsifying the extract with caffeoylquinic acids isolated from other sources, such as from coffee [Botsaris \& Alves, 2013].

The caffeoylquinic acids and the flavonoids maintain a production equilibrium by the plant. An unbalance must be seen with suspicion, as it is not normal for the plant physiology due to its high levels of caffeoylquinic acids and low levels of flavonoids, or vice versa. An adulterated sample, for example, in addition to the absence flavonoids is doubtful, as previously indicated, the amount of caffeoylquinic acids in abundance in the extract indicates adulteration, since naturally the plant does not produce such a high amount of this compound.

Few studies have demonstrated the quantification of equivalents of flavonoids in quercetin. However, when analyzing 5 commercial samples, they observed values of flavonoids equivalent in rutina ranging from $46,25 \pm$ 5,83 a $74,13 \pm 22,11 \mathrm{mg} \mathrm{EQ} / 100 \mathrm{~g}$ of extract. In our laboratory, we demonstrated that the results, despite the different standards used, it is possible to observe an amount of equivalents flavonoids in quercetin, 24 times lower than those reported in literature. On the other hand, the amount of phenolic compounds observed in our laboratory results was 10 times higher than reference values. The high values of the phenolic compounds observed in our laboratory results, probably can be due to presence of caffeoylquinic acids (chlorogenic acid, 1,5 tipfeoylquinic acid and cinarina). 
In view of the results, obtaining the dry extract of the artichoke proved to be effective in preparing a pharmaceutical ingredient and, at the same time, preserved the characteristics of special metabolites studied. This drying process consists of pulverization the liquid inside a chamber, submitted to a controlled air flow, obtaining the ultra-fast separation of the solids and solubles contained, ending with the recovery product in prowder.

Despite the discrepancy in the balance of the amount of the flavonoids and phenolic compounds is evident when compared with the literature. Additional studies with the quantification of phenolic acids and thin layer chromatography should be performed to ensure the quality of the raw material under study.

Thus, the extract presented good values of total polyphenols and flavonoids with minimal degradation of the quantified metabolites.

The daily intake of flavonoids and total polyphenols can be influenced mainly by the cultural habits from a certain population, which can lead to some divergences in relation to the daily concentration ingested between several populations. [Gary, 2003], reported that the daily total consumption of flavonoids by the world population can vary between $20 \mathrm{mg} /$ day, in countries like the United States of America, Denmark and Finland, to $70 \mathrm{mg}$ /day in the Netherlands.

Studies about the estimate intake of flavonoids and polyphenols by the brazilian population are scarce, where the only information were raised by [Arabbi Genovese \& Zakaria, 2014] and [Miranda et al., 2016], estimating the intake of approximately $60-106 \mathrm{mg} /$ day of flavonoids and $377,5 \mathrm{mg}$ /day of polyphenols, respectively.

On the other hand, some studies have shown that the treatment in rats with flavonoids extracted from grape seed $(50 \mathrm{mg} / \mathrm{kg} /$ day $)$, in the period of three weeks, demonstrated a significant result for atherosclerosis pathology. In this same study, it was observed that the coronary and aortic flow were recovered, in addition to an improvement in blood pressure [Giehl et al., 2007]. In some studies involving diabetic rats, [Vessal, Hemmati \& Vasei, 2003] demonstrated that the administration of two o-heterosides flavonoids, at a concentration of $100 \mathrm{mg} / \mathrm{kg}$, was able to decrease the blood glucose in rats 24 hours after the treatment. Otherwise, [16] observed the decrease of blood glucose in treated rats when administered between $10-15 \mathrm{mg} / \mathrm{kg}$ of flavonoid quercetin.

Therefore, the amount of flavonoids and total polyphenols administered daily to different biological models depends directly on the composition of the flavonoids. Considering that this concentration can vary between 10 to $100 \mathrm{mg} / \mathrm{kg}$ of mass of [Vessal, Hemmati \& Vasei, 2003], it was chosen to work with the administration of $200 \mathrm{mg} / \mathrm{kg} /$ day to the animals treated with artichoke extract.

The monitoring of the animals during the period of three experimental weeks showed that the diabetic animals presented a feed intake of $28,7 \pm 0,30 \mathrm{~g} / 300 \mathrm{~g}$ of animal mass, while the non-diabetic animals have ingested 20,4, $\pm 4 \mathrm{~g} / 300 \mathrm{~g}$ of animal mass. Otherwise, the water consumption was equal to $125,1 \pm 1,5 \mathrm{~mL}$ for te diabetic group and 46,1 $1,9 \mathrm{~g} / 300 \mathrm{~g}$ of animal mass, respectively (Graph 1and 2). Although the observation of an increase in consumption of water and feed in diabetic animals when compared to non-diabetic animals, the treatment with the extract was not able to improve the polydipsia and polyphagia in the diabetic animals treated with the artichoke extract.

Graph 1. Intake monitoring of feed 


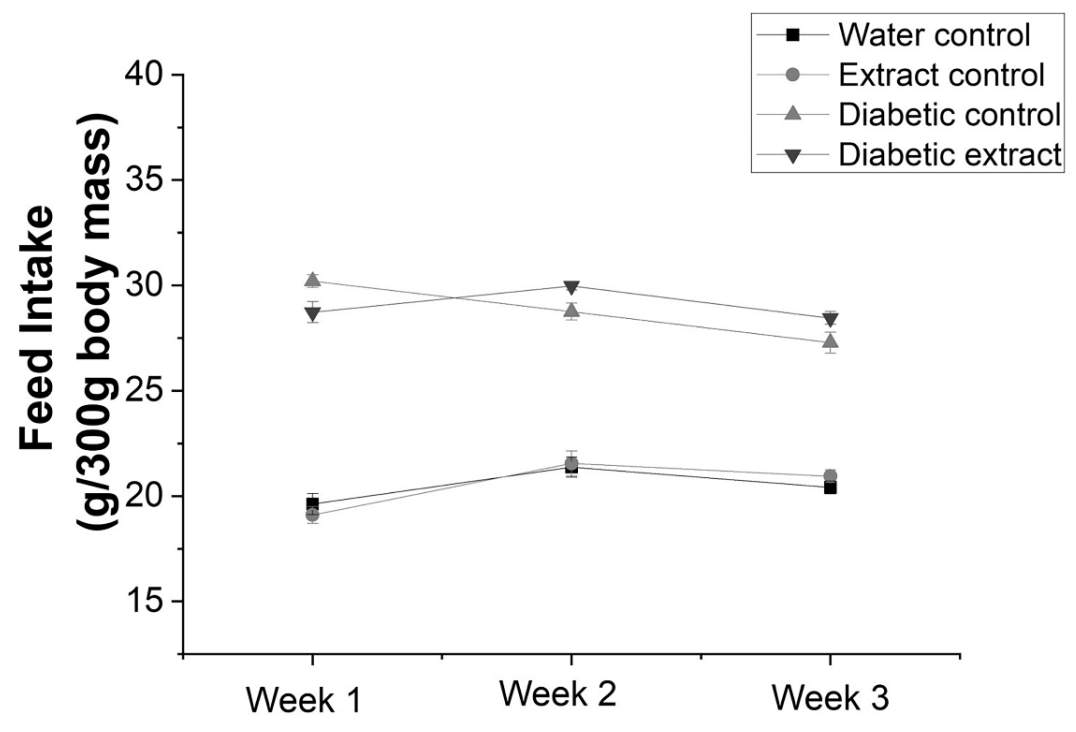

Font: Authored by the author

Graph 2. Intake monitoring of water

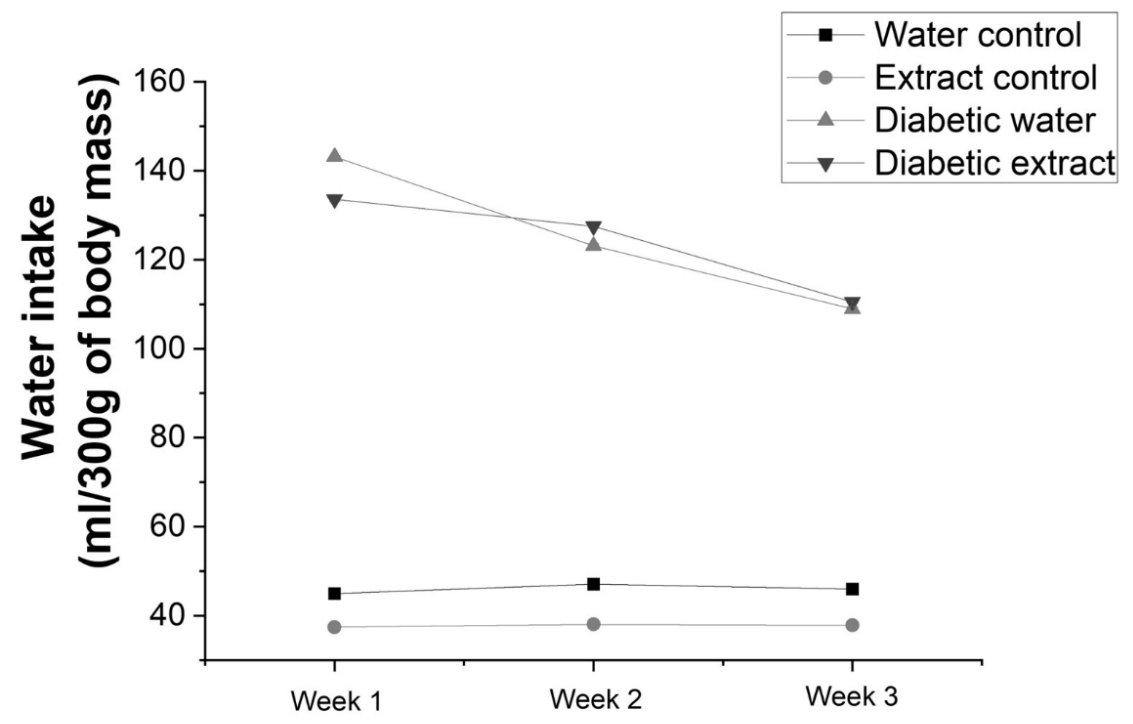

Font: Authored by the author

In the present study, the effect of the artichoke extract over the fasting blood glucose and fructosamine in diabetic rats were evaluated. As expected, fasting blood glucose was significantly higher in the "Diabetic group" when compared to animals in the "Non-diabetic group", "Extract" and "Diabetic extract", demonstrating that the induction protocol used was efficient. On the other hand, that was observed that the fasting 
blood glucose of the animals in the group "Diabetic extract" was statistically lower when compared to the blood glucose of animals in the group "diabetic" (Graph 3).

Graph 3. Effect of artichoke extract on fasting glycemia in diabetic rats

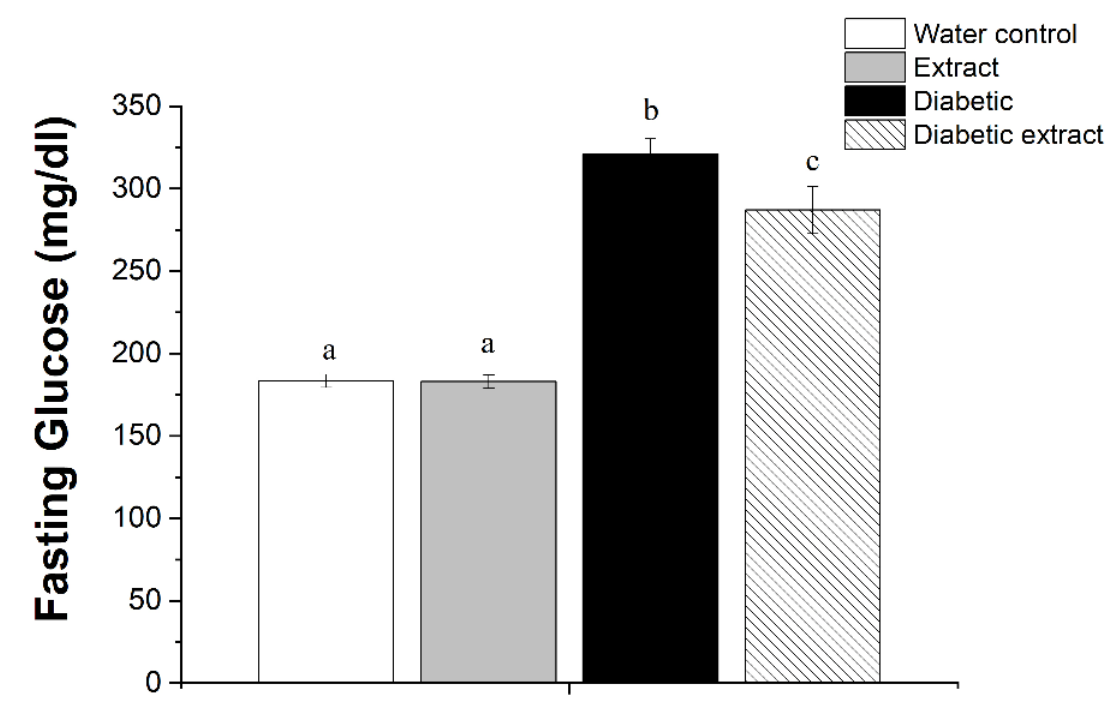

Font: Authored by the author

Legend: The results represent the medium \pm standard deviation of 8-10 determinations per treatment, estimated of serum levels of fasting glycemia. ANOVA was determined and the letters indicate that there was no significant difference of Tukey-Kramer test, adopting $\mathrm{p}<0,05$.

The determination of fasting blood glucose normally is used to assess short-term glycemic control, since it reflects momentary glycemic levels. On the other hand, fructosamines have a fundamental role in monitoring glycemic control and can be considered as parameters for the evaluation of glycemic control at medium term (Porto, De Oliveira \& Seara, 2009).

The treatment of diabetic animals with artichoke extract was able to decrease significantly levels of seric fructosamines (Graph 4);

Graph 4. Effect of artichoke extract on fructosamine in diabetic rats 


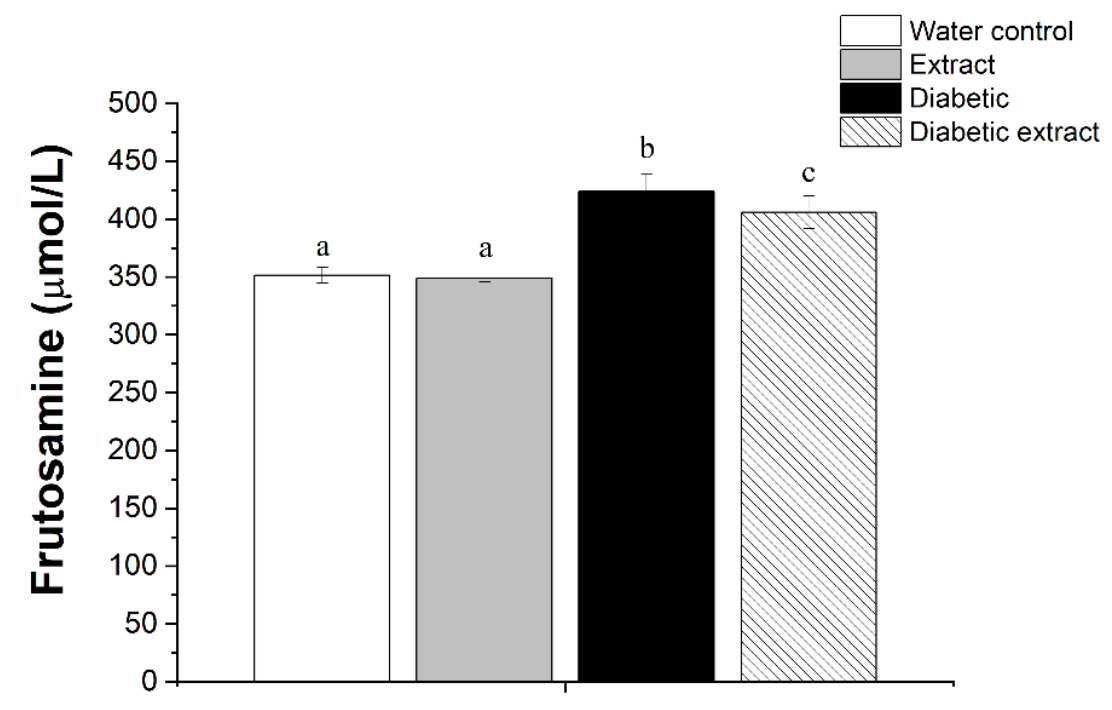

Font: Authored by the author

Legend: The results represent the medium \pm standard deviation of 8-10 determinations per treatment, estimated of serum levels of fructosamine. ANOVA was determined and the letters indicate that there was significant difference of Tukey-Kramer test, adopting $\mathrm{p}<0,05$.

The diuretic effect of artichoke helps the urea and toxic substances eliminate, developing a depurative action. One of the antioxidant compounds present in the artichoke is the vitamin E, which in the human body is soluble in fat and has an effect on the oxidative stress involved in aging and complications as diabetes (Lactantius 2002). The fact that the artichoke is rich in dietetic fibres gives the artichoke the properti to regulate intestinal activity, contributing to the control of blood glucose and cholesterol levels [Ceccarelli,, Curadi \& Picciarelli, 2010].

According to [Gebhardt, 1997], the extracts with a higher content of phenolic derivatives present a higher protection of the liver, as well as antioxidant activities (they can limit the oxidative stress and restore the endothelial functions). Probability, the caffeine derivatives have a role in therapeutic activities of the artichoke when administered in vitro, but not in isolation. The leaf artichoke extract is capable not only to increase the bile flow, by reducing the cholesterol levels, but also to reestablish this flow when it is inhibited. These effects are performed by luteolin and to a lesser extent by luteolin-7-o-glucoside, while the chlorogenic acid and 1,5-dicaffeoylquinic are almost inefficient.

The antioxidant activity of flavonoids is obviously linked to its structure and can be determined by the following factors: The reactivity as donor agent of hidrogenom or electrons, stability of the formed flavonyl radical, reactivity against others antioxidants, capacity to chelate transitions metals, solubility and interaction with membranes. At the same time, its capacity to kidnap free radicals is directly linked to its oxidation potential and to the species to be kidnapped, and the lower oxidation potential of the flavonoids, higher is its capacity as kidnapper of free radicals [Barreiros, David \& Juceni, 2006].

Quercetin actuates normalizing the plasmatic glucose levels, increasing the content of hepatic glycogen and inducing the enzymes hepatic glucokinase and hexokinase [Vessal, Hemmati \& Vasei, 2003]. The flavonoid naringenin is known to block the activity of the PI-3K in adipocytes and thus inhibiting the captivation of glucose. Another 14 flavonoids were investigated as possible inhibitory action on PI-3K, such as quercetin, luteolin, myricetin, apigenin and diosmetin which showed any type of inhibition on activity of the PI-3K 
[Agullo, Gamet-Payrastre, Manenti,Viala, Remesy, Chap \& Payrastre. 1997].

Some authors showed that the quercetin has several effects on glucose metabolism when administered orally to diabetic animals in a subchronic treatment. Effects such as the decrease of glycemics levels, increase of the hepatic hexokinase and glucokinase activity and normalization of the glucose tolerance curve, in addition to an increase in the number of the pancreatic islets. The authors linked these effects to the antioxidant potential that quercetin has and as this consequence, it would be regenerating pancreatic cells and increasing insulin secretion, therefore, these actions of the glucose metabolism would be due to the increased insulin secretion [Vessal, Hemmati \& Vasei, 2003].

According to [Salles, da Silva, Taniguthi, Ferreira, da Rocha, Vilegas., Dias, Pennacchi, Duarte, Rodrigues, Brigagão \& Paula. 2020] the dyslipidemic observed in diabetic animals can be attributed to the hyperglycemic shown by them. The hypercholesterolemia due to type $2 \mathrm{DM}$ has been linked to the increase of the atherogenic lipoproteins such as, low density lipoprotein (LDL) and very low density lipoprotein (VLDL).

However, it has been reported that in type $1 \mathrm{DM}$, an increase in the serum concentration of HDL cholesterol may be linked to high or normal concentrations of the other lipoproteins [Kahri, Groop, Viberti, Elliot \& Taskinen. 1993]. In this case, despite the high levels of HDL cholesterol, there is no reduction in cardiac risk in these individuals, since changes in the size, composition and structure of HDL may be present, compromising their functionality and negatively interfering with their antiatherogenic properties [Sviridov, Kingwell, Hoang, Dart \& Nestel. 2003].

In our studies, an increase in the concentration of total cholesterol and triglycerides in the serum of diabetic animals when compared to non-diabetic animals (Table 1), compatible with the metabolics alterations observed in diabetes mellitus.

Diabetic animals treated with the artichoke extracts showed serum levels of total cholesterol and triglycerides significantly lower than non-treated animals (Table 1).

Table 1 - Evaluation of lipid profile in serum of Wistar rats

\begin{tabular}{lll}
\hline Groups & Triglycerides $(\mathbf{m g} / \mathbf{d l})$ & Total cholesterol $(\mathbf{m g} / \mathbf{d l})$ \\
Non-diabetic & $39,7 \pm 2,10^{\mathrm{a}}$ & $78,9 \pm 1,92^{\mathrm{a}}$ \\
Extract & $59,9 \pm 3,34^{\mathrm{a}}$ & $89,8 \pm 1,61^{\mathrm{a}}$ \\
Diabetic & $74,35 \pm 2,97^{\mathrm{c}}$ & $126,6 \pm 5,27^{\mathrm{c}}$ \\
Diabétic Extract & $70,63 \pm 1,77^{\mathrm{b}}$ & $114,4 \pm 3,21^{\mathrm{b}}$ \\
\hline
\end{tabular}

Font: Authored by the author

Legend: The determinations were realized in serum samples gotten after euthanasia. The results represent the

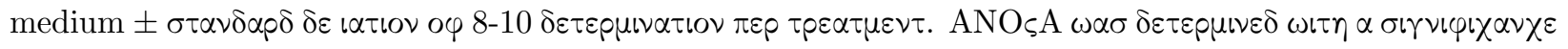
$\circ \varphi \pi<0,05$.

However, these results suggest that its action could be related to the reduction of the concentration of atherogenic lipoproteins in the serum of these animals, which can be justified by its increase in the glycemic control of these animals, as previously observed (Graph 3). [Salles, da Silva, Taniguthi, Ferreira, da Rocha, Vilegas., Dias, Pennacchi, Duarte, Rodrigues, Brigagão \& Paula. 2020] reports that recent studies have shown that the combined treatment with estatines and phytopharmaceuticals, have been capable to decrease the levels of the glycated hemoglobin, triglycerides, total cholesterol and LDL cholesterol in individuals between 40 and 60 of age with type 2 diabetes mellitus [Kianbakht, Nabati \& Abasi. 2016]. In this same study, the quantification of the amount of flavonoids, total polyphenols and quercetin, were attributed as the mainly responsible for the observed effects. However can not be discarded the fact that the reduction of the triglycerides and cholesterol is linked to the reduction of glucose, once it acts on the entire glycemic profile.

The artichoke is cited [Gonçalves, Moura, Rabelo, Barbosa-Filho, Cruz \& Cruz. 2000] as being capable of 
reducing the levels of lipids in plasma.[Lorenzi \& Matos. 2020], clinical trials in humans with the intake of substances content in artichoke leafs promoted an acute reduction of triglycerides levels. As described by [Anjo. 2004], substances such as insulin and fructooligosaccharide present in artichokes present effects as reducing the triglycerides levels.

Considering that the protein glycation has been pointed as one of the main mechanisms responsible for the glomerular lesions observed at diabetic nephropathy [Faria. 2001] serum creatinine levels in serum in animals from different groups in the study were evaluated (Graph 5). A significant increase in serum creatinine levels in the group of diabetic animals non-treated with artichoke extracts when compared to non-diabetic animals. No significant difference was observed in relation to the serum levels of creatinine when these two groups were compared.

Graph 5. Effect of artichoke extract on creatinine levels in diabetic rats

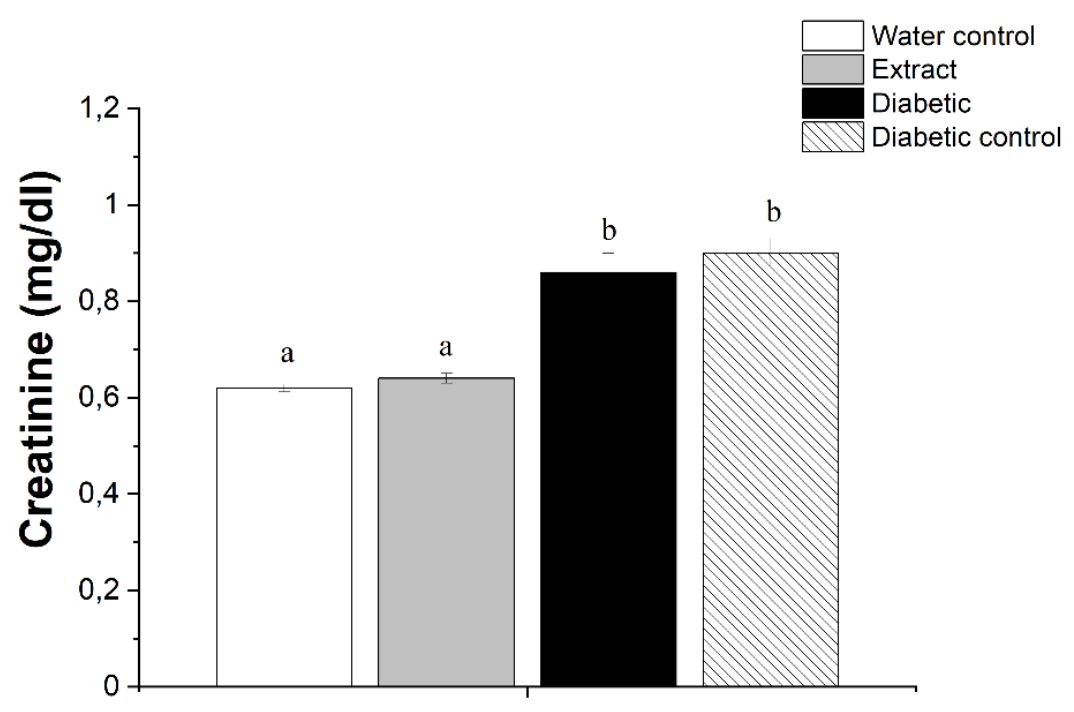

Font: Authored by the author

Legend: The results represent the medium \pm standard deviation of 8-10 determinations per treatment, estimated of serum levels of fructosamine. ANOVA was determined and the letters indicate that there was significant difference of Tukey-Kramer test, adopting $\mathrm{p}<0,05$.

The hyperglycemic, with consequent increase in ROS, reduces the levels of nitric oxide (NO) by activating the aldose reductase. The increase in the flow through the polyols route, induced by the increase in ROS, determines higher conversion of glucose to sorbitol, reducing NADPH and glutathione (intracellular antioxidant) and increasing the oxidative stress induced by hyperglycemia. Sorbitol is converted to fructose, resulting in an increase in the $\mathrm{NADH}: \mathrm{NAD}^{+}$ratio, which would increase the synthesis de diacylglycerol (DAG), the main physiological activator of protein kinase C (PKC) [Reis, Veloso, Mattos, Purish \& Nogueira. 2008].

\section{CONCLUSION}

According to the obtained results, it was possible to conclude that the plant species studied presented high concentrations of total polyphenols and low concentrations of flavonoids when compared to the literature. Phenolic compounds are mainly responsible for the therapeutic effects of artichoke, suggesting a possible 
indication as complementary treatment for chronic diseases non transmissibles. However, additional investigation about the rational use of this extract as complementary treatment, research of other phytochemical markers are necessary to establish safety recoveries that improve the rational quality of individuals who have chronic disease non transmissible.

The treatment of non-diabetic animals with the artichoke extract was capable of controlling the glycemic levels in short-term and medium-term, demonstrating a better analysis of lipidic profile. Despite these animals showing renal lesions installed due to the creatinine increase, it was not observed reduction of creatinine in

diabetic rats non-treated with the artichoke extract. The somatory of the beneficial effects showed in this study, surgery a possible complementary treatment to Diabetes mellitus with artichoke crude extract

\section{DECLARATION OF COMPETING INTEREST}

All the authors declare that they have no conflicting interests.

\section{REFERENCES}

Malta, Deborah Carvalho, \& Silva Jr, Jarbas Barbosa da. (2013). O Plano de Ações Estratégicas para o Enfrentamento das Doenças Crônicas Não Transmissíveis no Brasil e a definição das metas globais para o enfrentamento dessas doenças até 2025: uma revisão. Epidemiologia e Serviços de Saúde , 22 (1), 151-164. https://dx.doi.org/10.5123/S1679-49742013000100016

MOREIRA, H.G,; SETTE, J. B. C.; KEIRALlA, L. C. B.; AlVES, S. G.; PIMENTA, E.; SOUZA, M.;... AMODEO.; (2008) Diabetes mellitus, hipertensão arterial e doença renal crônica: estratégias terapêuticas e suas limitações. Rev Bras Hipertens, 15(2) , 111-116.

Newman, D. J., \& Cragg, G. M. (2016). Natural Products as Sources of New Drugs from 1981 to 2014. Journal of natural products ,79 (3), 629-661.https://doi.org/10.1021/acs.jnatprod.5b01055

Singleton, V.L., Orthofer, R., \& Lamuela-Raventós, R.M. (1999). Analysis of total phenols and other oxidation substrates and antioxidants by means of Folin-Ciocalteu reagent. Methods in Enzymology, 299 , 152-178.

Souza, T.M., Santos, L.E., Moreira, R.R.D., \& Rangel, V.L.B.I.. (2005). Avaliação da atividade fotoprotetora de Achillea millefolium L. (Asteraceae). Revista Brasileira de Farmacognosia , 15 (1), 36-38. https://doi.org/10.1590/S0102-695X2005000100008

Jaouhari, J. T., Lazrek, H. B., \& Jana, M. (2000). The hypoglycemic activity of Zygophyllum gaetulum extracts in alloxan-induced hyperglycemic rats. Journal of ethnopharmacology , 69 (1), 1720.https://doi.org/10.1016/s0378-8741(99)00064-1

Beecher G. R. (2003). Overview of dietary flavonoids: nomenclature, occurrence and intake. The Journal of nutrition , 133 (10), 3248S-3254S.https://doi.org/10.1093/jn/133.10.3248S

Burtis, C. A., Ashwood, E. R., Border, B., \& Tietz, N. W. (2001). Tietz fundamentals of clinical chemistry . Philadelphia: W.B. Saunders.

Miranda, A. M., Steluti, J., Fisberg, R. M., \& Marchioni, D. M. (2016). Dietary intake and food contributors of polyphenols in adults and elderly adults of Sao Paulo: a population-based study. The British journal of nutrition , 115 (6), 1061-1070.https://doi.org/10.1017/S0007114515005061

Ramaiya, Shiamala \& Bujang, Japar Sidik \& Zakaria, Muta. (2014). Genetic Diversity in Passiflora Species Assessed by Morphological and ITS Sequence Analysis. TheScientificWorldJournal. 2014. 598313. $10.1155 / 2014 / 598313$.

Kelly, W., Garcia, P., McDermott, S., Mullen, P., Kamguia, G., Jones, G., Ubiera, A., \& Göklen, K. (2013). Experimental characterization of next-generation expanded-bed adsorbents for capture of a recombinant protein expressed in high-cell-density yeast fermentation. Biotechnology and applied biochemistry, 60(5), 510-520.https://doi.org/10.1002/bab.1133 
BOTSARIS, A. S.; ALVES, L. F. (2013). Cynara scolymus L. (Alcachofra). Revista Fitos, [S.l.], v. 3, n. 02, p. 51-63.

Arabbi, P. R., Genovese, M. I., \& Lajolo, F. M. (2004). Flavonoids in vegetable foods commonly consumed in Brazil and estimated ingestion by the Brazilian population. Journal of agricultural and food chemistry, 52 (5), 1124-1131.https://doi.org/10.1021/jf0499525

Gihel, M. R.; Dal Bosco, S. M.; Laflor, C. M.; Weber, B. (2007). Efficacy of grape, red wine and grape juice flavonoids in the prevention and secondary treatment of atherosclerosis. Sci. med;17(3):145-155.

Vessal, M., Hemmati, M., \& Vasei, M. (2003). Antidiabetic effects of quercetin in streptozocin-induced diabetic rats. Comparative biochemistry and physiology. Toxicology $\&$ pharmacology : CBP ,135C (3), 357364. https://doi.org/10.1016/s1532-0456(03)00140-6

Barbosa, Júnia Helena Porto, Oliveira, Suzana Lima de, \& Seara, Luci Tojal e. (2009). Produtos da glicação avançada dietéticos e as complicações crônicas do diabetes. Revista de Nutrição ,22 (1), 113-124. https://doi.org/10.1590/S1415-52732009000100011

V. Lactantius; N. Cicco; R. Terzano; S. Raccuia; G. Mauromicale; D. De Vênus; V. A salada (2002). Potenziale utilizzo di sottoprodotti derivanti dalla lavorazione industriale Del carciofo: Antiossidanti di natura fenolica ed inulina. In: Atti Xix Convegno Sica. Anais Reggio Calabria: Tipografia Iiriti. v.1. 251-258.

Ceccarelli, N., Curadi, M., Picciarelli, P. (2010). Globe artichoke as a functional food. Mediterr J Nutr Metab 3, 197-201.https://doi.org/10.1007/s12349-010-0021-z

Gebhardt R. (1997). Antioxidative and protective properties of extracts from leaves of the artichoke (Cynara scolymus L.) against hydroperoxide-induced oxidative stress in cultured rat hepatocytes. Toxicology and applied pharmacology , 144 (2), 279-286. https://doi.org/10.1006/taap.1997.8130

Barreiros, André L. B. S., David, Jorge M., \& David, Juceni P.. (2006). Estresse oxidativo: relação entre geração de espécies reativas e defesa do organismo. Química Nova , 29 (1), 113-123. https://dx.doi.org/10.1590/S0100-40422006000100021

Agullo, G.; Gamet-Payrastre, L.; Manenti, S.; Viala, C.; Remesy, C.; Chap, H.; Payrastre, B. (1997) Relationship between flavonoid structure and inhibition of phosphatidylinositol 3-kinase: a comparison with tyrosine kinase and protein kinase C inhibition. Biochemical Pharmacology, v. 53, p. 1649-1657.

Salles, B., da Silva, M. A., Taniguthi, L., Ferreira, J. N., da Rocha, C. Q., Vilegas, W., Dias, P. H., Pennacchi, P. C., Duarte, S., Rodrigues, M. R., Brigagão, M., \& Paula, F. (2020). Passiflora edulis Leaf Extract: Evidence of Antidiabetic and Antiplatelet Effects in Rats. Biological $\& 3$ pharmaceutical bulletin , 43 (1), 169-174. https://doi.org/10.1248/bpb.b18-00952

Kahri J; Groop Ph; Viberti G; Elliot T \& Taskinen Mr (1993). Regulation of apolipoprotein A-1- lipopotreins in IDDM. Diabete s; 42:1281-8.https://doi.org/10.2337/diab.42.9.1281

Sviridov D; Kingwell B; Hoang A; Dart A; Nestel P. (2003) Single session exercise stimulates formation of pre beta 1-HDL in leg muscle. The Journal of Lipid Research, 44, 522-526.

Kianbakht, S., Nabati, F., \& Abasi, B. (2016). Salvia officinalis (Sage) Leaf Extract as Add-on to Statin Therapy in Hypercholesterolemic Type 2 Diabetic Patients: a Randomized Clinical Trial.International journal of molecular and cellular medicine ,5 (3), 141-148.

Gonçalves MCR, Moura LSA, Rabelo LA, Barbosa-Filho JM, Cruz HMM, Cruz J (2000). Produtos naturais inibidores da enzima HMG CoA redutase. Rev Bras Farm 81 : 63-71. 
Lorenzi, H.; Matos, F. J. A. (2020). Plantas medicinais no Brasil nativas e exóticas. Instituto Plantarum de Estudos da Flora, . 512.

Anjo, D. F. C. (2004). Alimentos funcionais em angiologia e cirurgia vascular. Jornal Vascular Brasileiro, v. 3, p.145-154.

Faria, J.B.L. (2001) Fisiologia e fisiopatologia: Patogênese da nefropatia diabética. Jornal Brasileiro de Nefrologia . v. 23, n. 2, p. 121-129

Reis J. S, Veloso C. A, Mattos R. T, Purish S, Nogueira. M. J. A. (2008) Oxidative stress: a review on metabolic signaling in type 1 diabetes.Arq Bras Endocrinol Metabol. 1096-105. doi: 10.1590/s000427302008000700005 . PMID: 19082297.

Shiffrin, E. L.; Lipman, M. L. Mann, J. F.E (2007). Chronic Kidney Disease: Effects on the Cardiovascular System. Circulation . vol. 116: 85-97. https://doi.org/10.1161/CIRCULATIONAHA.106.678342

King AJ. (2012) The use of animal models in diabetes research. Br J Pharmacol ; 166(3):877-894. doi:10.1111/j.1476-5381.2012.01911.x

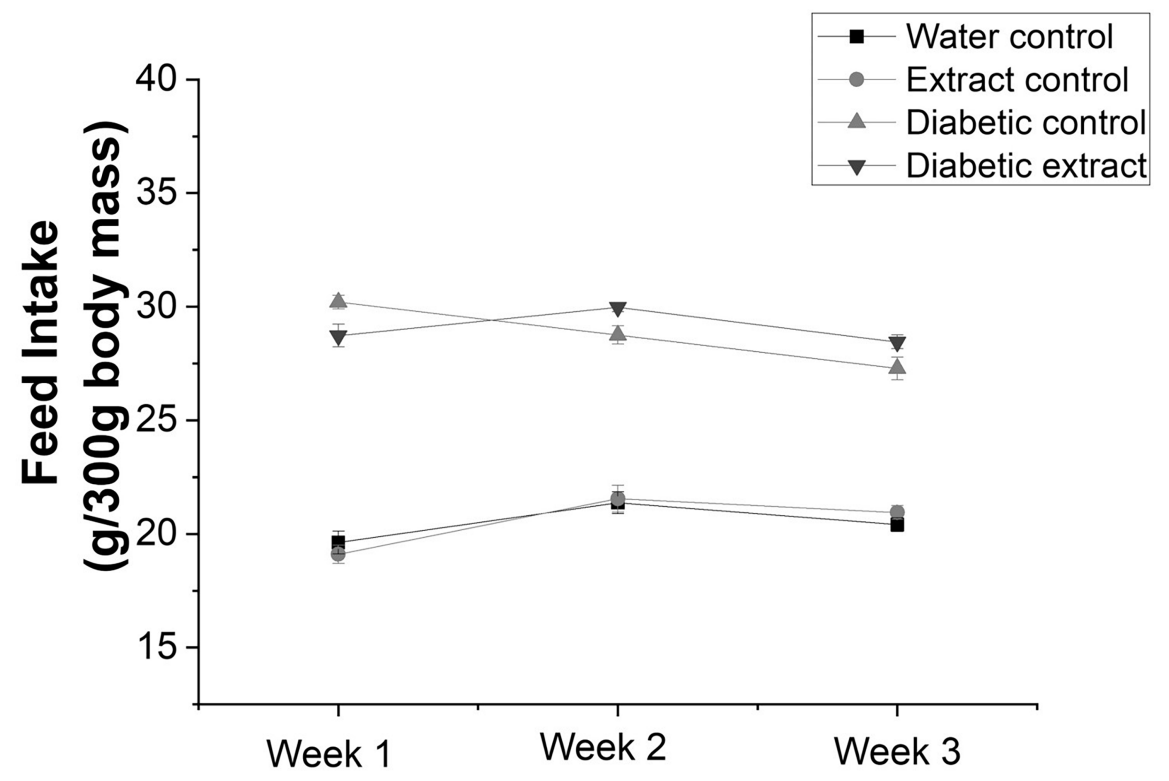



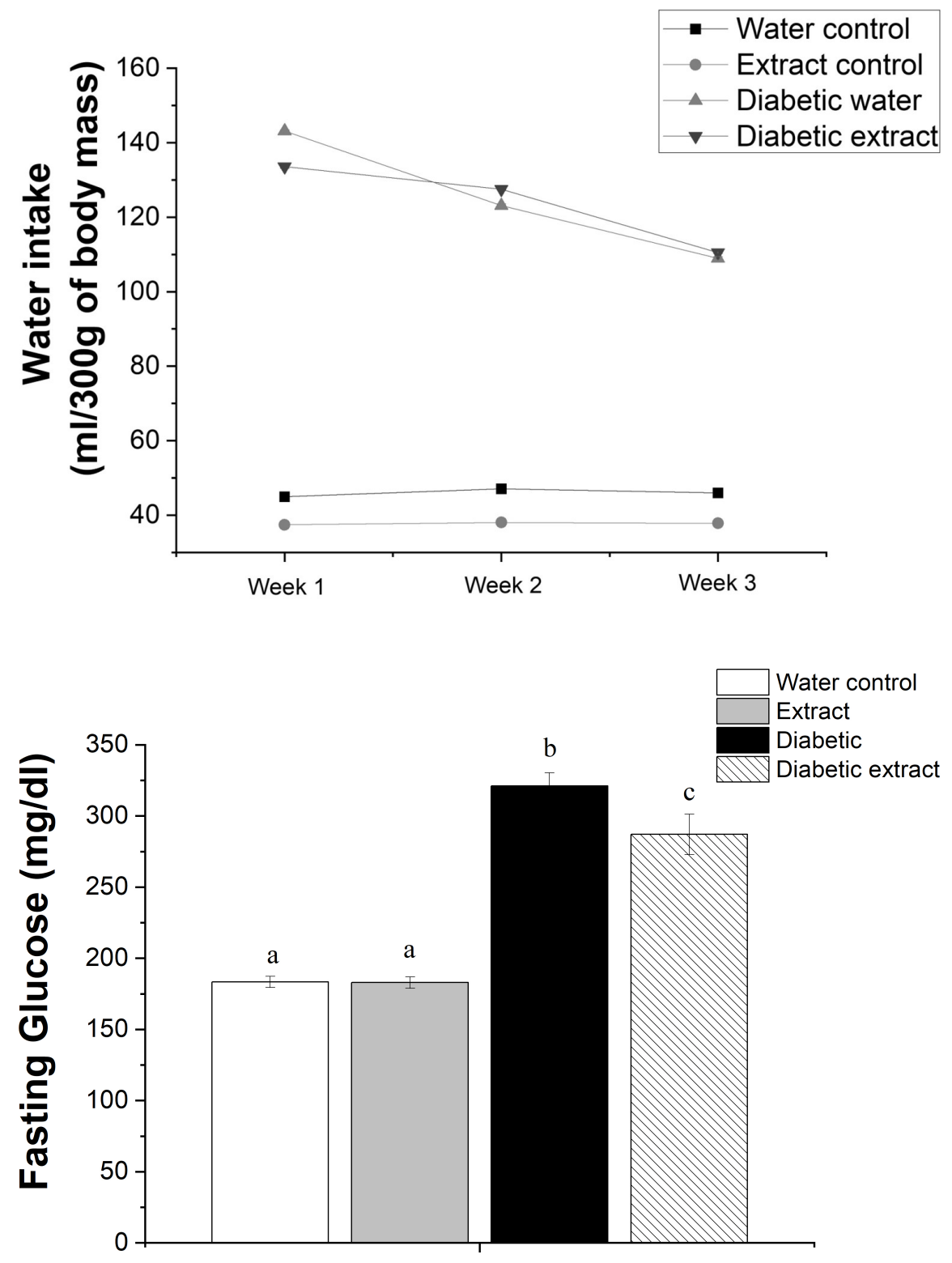

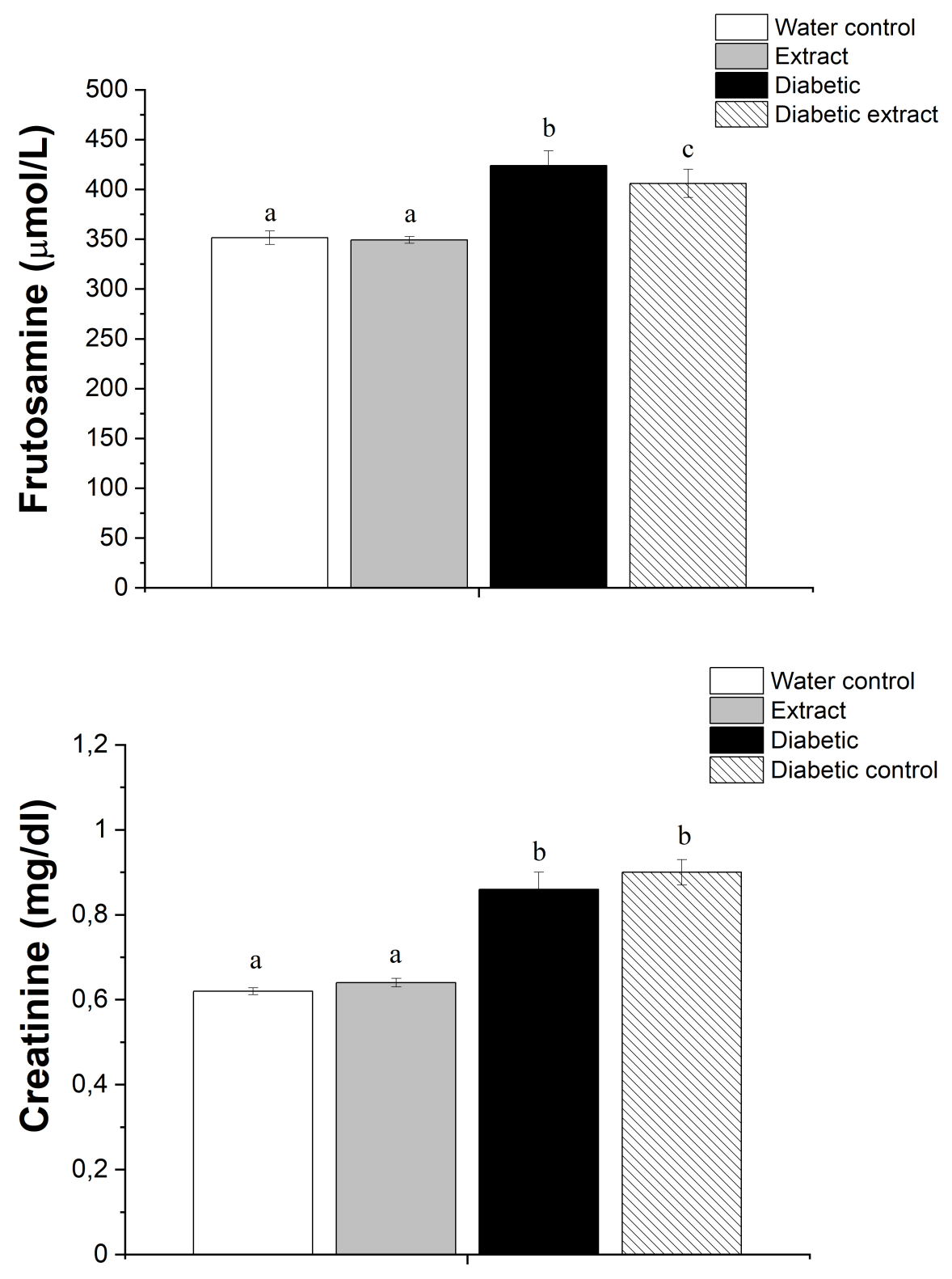